\title{
Primary pleural angiosarcoma as a mimicker of mesothelioma: a case report
}

\author{
Yu-Chien Kao ${ }^{1}$, Jyh-Ming Chow ${ }^{2}$, Kum-Min Wang ${ }^{3}$, Chia-Lang Fang ${ }^{1}$, Jan-Show Chu ${ }^{4}$ and Chi-Long Chen ${ }^{1 *}$
}

\begin{abstract}
Primary pleural angiosarcoma is a rare and clinically aggressive tumor. Patients usually present with chest pain, dyspnea, hemoptysis and/or cough. Radiologic studies reveal diffuse pleural thickening and pleural effusion with or without mass lesion. The clinical and radiological features both resemble those of mesothelioma, and its definite diagnosis requires careful histologic examination. However, frequent epithelioid feature and immunoreactivity to cytokeratin in primary pleural angiosarcoma further complicate the pathologic diagnosis. The use of proper immunohistochemical stains is often needed to support endothelial differentiation in the tumor cells and to exclude metastatic carcinoma and mesothelioma. We report the case of a 49-year-old male patient with primary pleural angiosarcoma, who presented with initial hemothorax, followed by a rapid progress to an inoperable status.

Virtual Slides: The virtual slide(s) for this article can be found here: http://www.diagnosticpathology.diagnomx.eu/ vs/1059343251633446
\end{abstract}

Keywords: angiosarcoma, pleura, mesothelioma, sarcoma, pathology

\section{Background}

Angiosarcoma is an uncommon malignant tumor of endothelial differentiation. It accounts for about $1 \%$ of all soft tissue malignancies and most commonly arises in skin, soft tissue, breast, liver, bone and spleen [1].

Primary pleural angiosarcoma (PPA) is a rare occurrence. Since its first description in 1943,[2] only 39 reported cases of PPA have been published [1-22]. Patients almost always die of the disease within months. Definite diagnosis is usually not possible using the examination of cytology or small biopsy specimens, but often requires that of decortication or resection specimens. The histologic picture of biphasic spindle and epithelioid tumor cells along with immunoreactivity to epithelial markers, such as cytokeratin and CK7, may lead to an erroneous diagnosis of mesothelioma or metastatic sarcomatoid carcinoma. Identifying areas showing vasoformative tendency and immunostains with endothelial markers, such as CD31, CD34, factor VIII and FLI-1, are diagnostically important.

\footnotetext{
* Correspondence: chencl@tmu.edu.tw

${ }^{1}$ Department of Pathology, Wan Fang Hospital, Taipei Medical University, Taiwan

Full list of author information is available at the end of the article
}

We describe herein a case of PPA, to highlight its aggressive clinical behavior and the diagnostic pitfalls.

\section{Case presentation}

\section{Clinical summary}

A 49 year-old-male patient presented with intermittent right chest pain for one month. The pain progressed with exertional dyspnea. He had a 10-year history of asthma under regular medical treatment and was an exsmoker (half package-per-day for 20 years in the past) who quit 10 years ago. He did not have any history of asbestos exposure or tuberculous infection. In physical examination, breathing sounds were decreased at the right lung. Chest radiography and computed tomography revealed right-side loculated pleural effusion with pleural thickening but without mass lesion (Figure 1). Fine needle aspiration showed some bloody and sticky pleural effusion. The value of hematocrit of the effusion was $39.5 \%$ (peripheral blood hematocrit: $38.9 \%$ ). Cytologic examination of the pleural effusion showed negative for malignancy. Thoracoscopic examination revealed diffuse blood clot coating and thickening of the visceral and parietal pleura over the right hemithorax. $\mathrm{He}$ received thoracoscopic decortication of the pleura.
C Biomed Central

() 2011 Kao et al; licensee BioMed Central Ltd. This is an Open Access article distributed under the terms of the Creative Commons Attribution License (http://creativecommons.org/licenses/by/2.0), which permits unrestricted use, distribution, and reproduction in any medium, provided the original work is properly cited. 


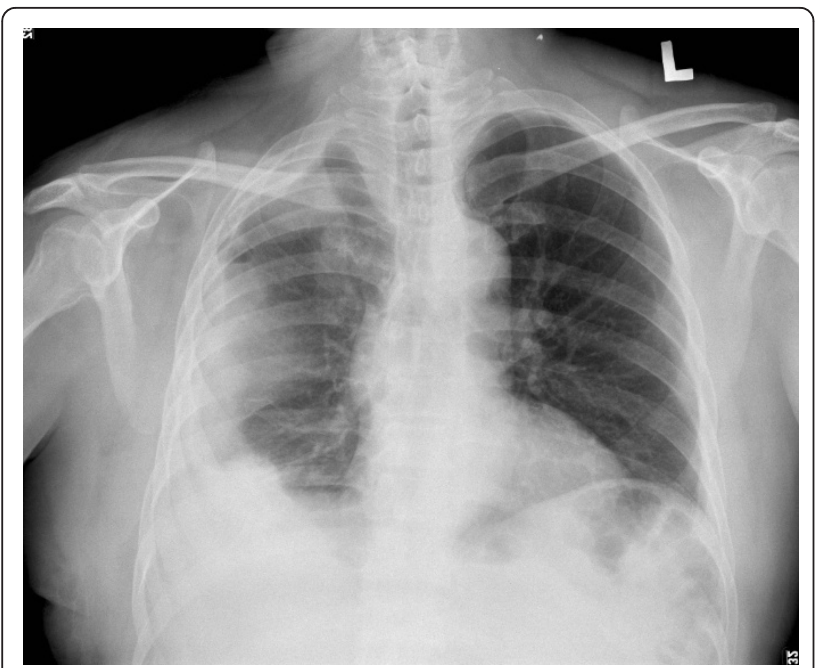

Figure 1 Chest roentgenogram. Plain chest film showed right-side loculated pleural effusion.

Subsequent staging image series showed no evidence of metastatic lesion in brain, bone and lung.

One month later, open thoracotomy revealed tumor mass extending along the previous surgical wound and encasing the right pulmonary hilum. Curative resection could not be done, and the patient received an excisional biopsy of the tumor.

\section{Pathologic findings}

Histologically, the specimens showed an extensive hemorrhagic background with epithelioid tumor cells arranged in solid sheets and discohesive cells separated by abundant red blood cells (RBCs) (Figure 2A-B). Infiltrative growth of the tumor cells in a hyalinized to fibrous background and between skeletal muscles was also present. The tumor cells had pleomorphic nuclei, irregular nuclear contour, occasional binucleation, vesicular chromatin, prominent nucleoli and abundant eosinophilic cytoplasm, giving an epithelioid feature. Rudimentary and anastomosing vascular channels and Intracytoplasmic lumens containing $\mathrm{RBCs}$ were seen in areas (Figure 2C-D). Spindle tumor cells were observed as a minor component of the tumor. The results of immunohistochemical stains showed diffuse positive staining for CD31, FLI-1, cytokeratin (AE1/AE3) and CK7 (Figure 3A-B), whereas CD34, factor VIII, and mesothelial markers including calretinin, CK5/6, HBME-1, and WT-1 were negative. An angiosarcoma was diagnosed. The patient then received radiotherapy (3750 cGy with 15 fractions), five cycles of chemotherapy with mesna, ifosfamide, doxorubicin and dacarbazine, two cycles of cisplatin and doxorubicin and three cycles of doxorubicin, etoposide and thalidomide. He was alive with the disease nine months after the diagnosis was made.

\section{Discussion}

PPA is an aggressive and rapidly fatal disease. Only 39 cases have been reported in the literature[1-22] after excluding epithelioid hemangioendothelioma. Together with our patient, the ages of the patients ranged from 33 to 79 years (mean: 59.1 years) with male predominance (4:1, Figure 4). The most common presentation is chest pain (47.5\%), followed by dyspnea (35\%), hemoptysis $(27.5 \%)$, cough $(15 \%)$ and weight loss $(10 \%)$. Radiologic examinations usually show unilateral or bilateral effusion (70\%) and diffuse pleural thickening (40\%), simulating the presentation of mesothelioma. Mass lesions are seen in about half of the patients (54.3\%) [2-7,9,10,14,20-22].

The effusions are usually bloody. Cytologic examination of the pleural effusion is rarely helpful in making the diagnosis. In the seven cases with available cytologic examination results, $[1,8,9,13,19,20,22]$ presence of atypical cells was described in only one case [20]. Most patients were diagnosed by surgical excision $(32.5 \%$, including debulking excision, pleurectomy and decortication) $[3,5,7,9,12,13,15,17,18,20]$ or autopsy in rapidly lethal cases $(27.5 \%)$ [2,4,5,8,10,21,22]. Using non-invasive biopsy and surgical biopsy, the patients were diagnosed as PPA in a smaller proportion of cases $(17.5 \%$ and $10 \%$, respectively) $[1,5,6,14,16,19]$. Six out of 40 patients received a non-diagnostic biopsy $[8,9,13,19,21,22]$. Thus, in the context of refractory bloody pleural effusion of uncertain etiology, we suggest that surgical biopsy or excision should be considered even without mass lesion.

The histologic features show malignant spindle and/or epithelioid neoplasm with areas of vasoformative nature, such as vascular spaces lined by atypical tumor cells and intracytoplasmic lumen containing RBCs. Epithelioid features were mentioned in the majority of cases (72.5\%) and constituted variable proportion of the tumors [1,5-15,17-19]. The differential diagnosis of a biphasic pleural tumor mainly includes mesothelioma and sarcomatoid carcinoma. In general, mesothelioma shows more monotonous tumor cells with less degree of cytologic atypia. Intracytoplasmic lumen can be seen both in angiosarcoma and mesothelioma, but intraluminal RBCs are not seen in mesotheliomas [11]. Sarcomatoid carcinoma less likely manifests as diffuse pleural involvement. The carcinomatous component and clinical history would aid in diagnosis.

Immunohistochemical stains have an important role in differential diagnosis. Expression of at least one of the endothelial markers including CD31, CD34, factor VIII and FLI-1, is required to confirm the diagnosis of angiosarcoma. Among them, CD31 is considered to be the most sensitive and specific [1]. Epithelial markers can be expressed in angiosarcoma, especially in the epithelioid 


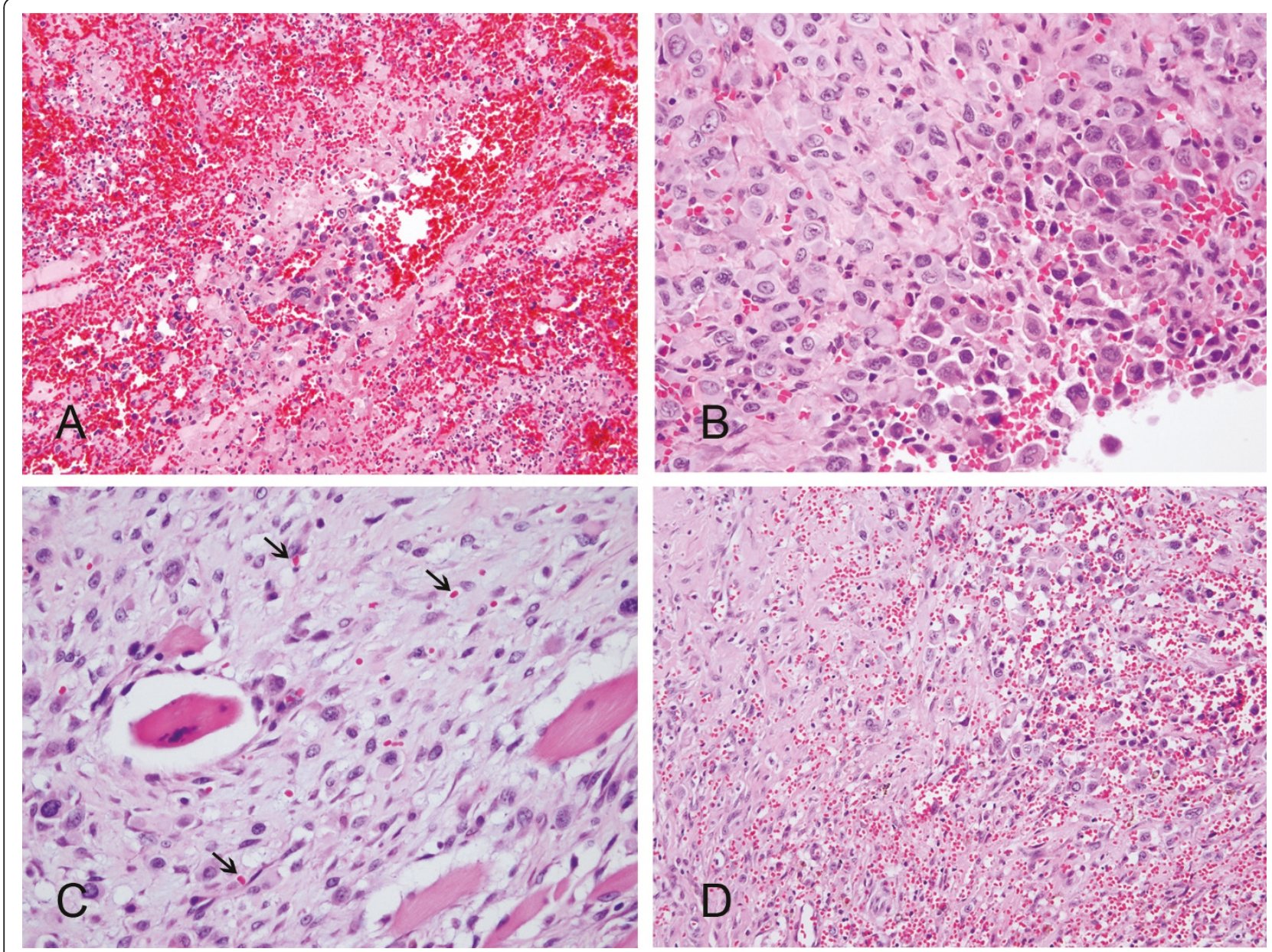

Figure 2 Histomorphology of the decortication specimen. Pleural angiosarcoma with scattered tumor cells in the hemorrhagic background (A). Solid sheets of epithelioid tumor cells can simulate mesothelioma and/or carcinoma (B). Intracytoplasmic lumen containing red blood cells $(C$, arrowhead) and anastomosing vascular spaces (D) are evidence of endothelial differentiation (hematoxylin-eosin, $\times 200[A, D]$ and $\times 400[B, C]$ ).

variant [23]. Positive cytokeratin staining was found in $60.9 \%$ cases of PPA (14 of 23, including our patient) $[1,5,11,14,15]$. Immunoreactivity to CAM5.2, CK7, CK8 or CK18 has also been reported [1,13,14]. Epithelial membrane antigen was negative in all those 14 cases with available results $[5,6,12,16,19,20]$. The expression of epithelial markers can be misleading in pathologic diagnosis. One should bear in mind that cytokeratin is also frequently expressed in epithelioid vascular tumors. Although the expression pattern of cytokeratin can range from diffuse and strong to focal and weak in distribution, it is usually not as strong as that in carcinoma or mesothelioma [17]. Mesothelial markers such as calretinin, CK5/6, HBME-1 and WT-1, are used to exclude malignant mesothelioma.

The etiologic factors in most cases of PPA are still unknown. Some case reports from Japan indicated the relationship with tuberculous pyothorax $(\mathrm{n}=11)$, $[5,15,21]$ while some cases from western countries had history of asbestos exposure $(n=4)[7,10]$ or radiotherapy $(\mathrm{n}=1)$ [11]. Association with tuberculosis has been first described by Myoui et al. in 3 out of 4 PPA patients [24]. Based on a series of autopsy cases, Aozasa et al. later reported six additional PPA patients associated with tuberculosis and postulated 3,600-fold increased risk of PPA in pyothorax patients [5]. But, Hattori et al. suggested that pyothorax-associated angiosarcoma often manifest as chest wall soft tissue tumors instead of diffuse pleural involvement and should be separated from PPA [25]. Attanoos et al reported three PPA patients with history of asbestos exposure [10]. However, only one of them had typical asbestos bodies in the lung and increased asbestos fiber content by mineral analysis. One patient with history of previous radiotherapy for ovarian carcinoma developed simultaneous pleural and peritoneal angiosarcoma [11]. Our patient did not have any history of tuberculosis, asbestos exposure or radiotherapy. 


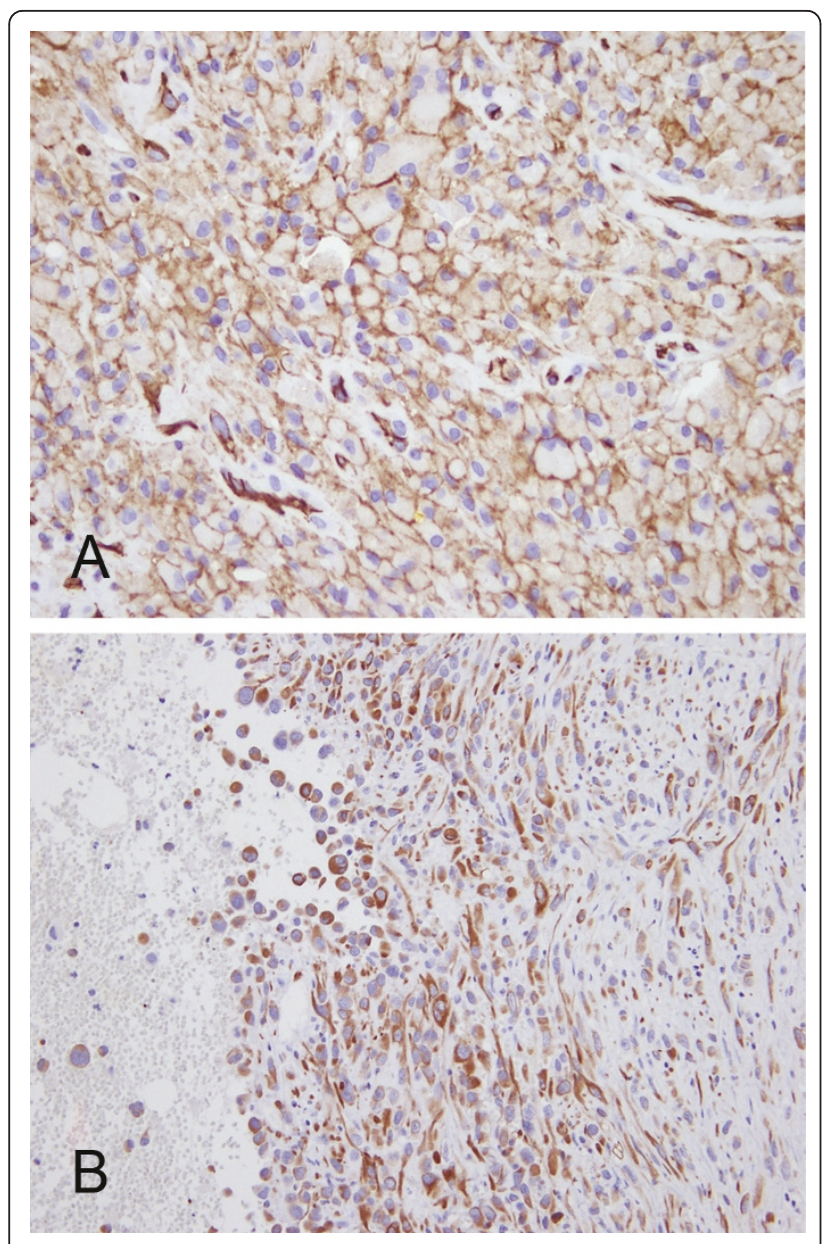

Figure $\mathbf{3}$ Immunohistochemical stains. Diffuse CD31 positivity (A) indicates the vascular nature of the tumor cells. Diffuse

immunoreactivity for cytokeratin stain (B) could be a diagnostic pitfall. $(\times 400[\mathrm{~A}]$ and $\times 200[\mathrm{~B}])$

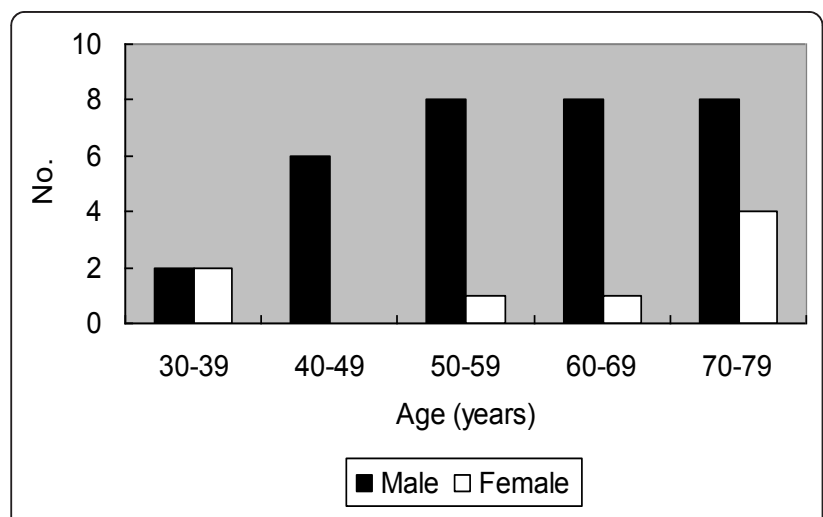

Figure 4 Age and sex distribution of reported cases of primary pleural angiosarcoma. Male predominance was shown in the age group of 40-79 years.

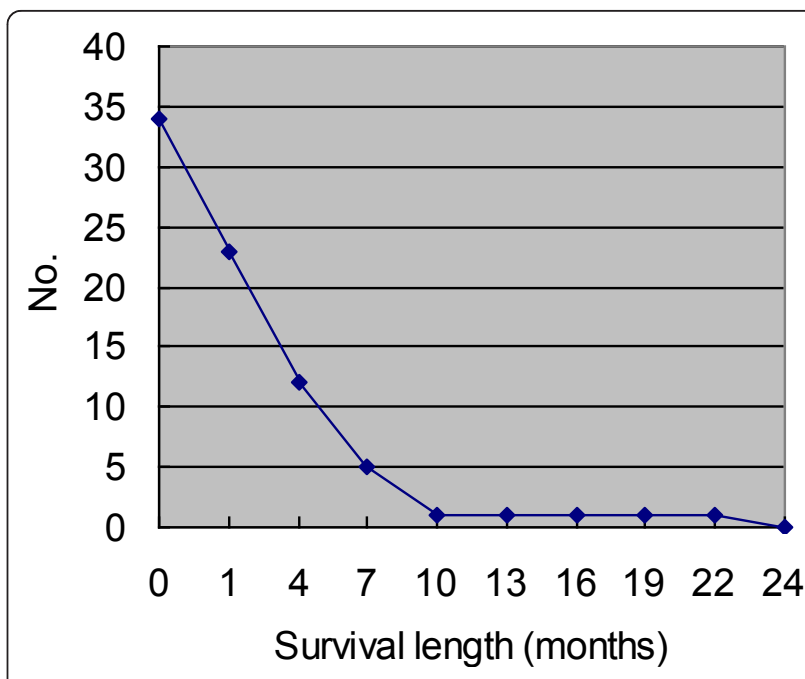

Figure 5 Survival length of reported available 34 cases of primary pleural angiosarcoma. Most patients died of disease within several months, and all of them died by the end of 24 months.

The treatments of angiosarcoma include surgical excision, radiotherapy and/or chemotherapy. However, the clinical course is usually rapidly fatal, regardless of treatment modalities. Seventy percent of the patients died of disease within 7 months (Figure 5). The prognosis is even worse than angiosarcoma of other organs [23]. According to the occurring frequency, metastatic sites reported in the literature include lymph node, adrenal gland, bone, brain, oral cavity, liver, skin, spleen, gastrointestinal tract, kidney and spinal cord $[2,3,5,8,15,18,19]$. In addition to nodal metastasis $(n=6)$ as in epithelioid angiosarcoma of other organs,[23] autopsied cases of PPA reported by Aozasa et al. show preference of adrenal gland metastasis $(\mathrm{n}=5)$ [5].

\section{Conclusion}

In conclusion, PPA is a highly malignant disease, which may mimic mesothelioma clinically, radiologically and even pathologically. The diagnostic pitfalls include mesotheliomatous growth pattern with diffuse pleural involvement, biphasic histomorphologic pattern and immunoreactivity to cytokeratin. An accurate diagnosis requires careful pathologic examination to identify the evidence of endothelial differentiation aided with immunohistochemical stains.

\section{Consent}

Written informed consent was obtained from the patient for publication of this Case Report and any accompanying images. A copy of the written consent is available for review by the Editor-in-Chief of this journal 
List of abbreviations used

PPA: primary pleural angiosarcoma; RBC: red blood cells.

\section{Author details}

'Department of Pathology, Wan Fang Hospital, Taipei Medical University, Taiwan. ${ }^{2}$ Division of Hematology and Medical Oncology, Department of Internal Medicine, Wan Fang Hospital, Taipei Medical University, Taiwan. ${ }^{3}$ Division of Thoracic and Cardiovascular Surgery, Department of Surgery, Wan Fang Hospital, Taipei Medical University, Taiwan. ${ }^{4}$ Department of Pathology, Taipei Medical University Hospital, Taiwan.

\section{Authors' contributions}

YCK participated in drafting the manuscript and literature review. JMC and KMW were responsible for acquisition of clinical data, follow-up information and the surgery (KMW). CLF, JSC and CLC participated in making the histopathological diagnosis, conception of the idea and revising the manuscript. All authors have read and approved the final manuscript.

\section{Competing interests}

The authors declare that they have no competing interests.

Received: 12 November 2011 Accepted: 30 December 2011

Published: 30 December 2011

\section{References}

1. Dainese E, Pozzi B, Milani M, Rossi G, Pezzotta MG, Vertemati G, Tricomi P, Sessa F: Primary pleural epithelioid angiosarcoma. A case report and review of the literature. Pathol Res Pract 2010, 206(6):415-419.

2. Stout AP: Hemangio-Endothelioma: A Tumor of Blood Vessels Featuring Vascular Endothelial Cells. Ann Surg 1943, 118(3):445-464.

3. Ximenes M, Miziara $\mathrm{HL}$ : Hemangioendothelioma of the lung and pleura: report of three cases. Int Surg 1981, 66(1):67-70.

4. McCaughey WT, Dardick I, Barr JR: Angiosarcoma of serous membranes. Arch Pathol Lab Med 1983, 107(6):304-307.

5. Aozasa K, Naka N, Tomita Y, Ohsawa M, Kanno H, Uchida A, Ono K: Angiosarcoma developing from chronic pyothorax. Mod Pathol 1994, 7(9):906-911.

6. Nappi O, Swanson PE, Wick MR: Pseudovascular adenoid squamous cell carcinoma of the lung. Hum Pathol 1994, 25(4):373-378.

7. Lin BT, Colby T, Gown AM, Hammar SP, Mertens RB, Churg A, Battifora H: Malignant vascular tumors of the serous membranes mimicking mesothelioma. A report of 14 cases. Am J Surg Pathol 1996, 20(12):1431-1439.

8. Falconieri G, Bussani R, Mirra M, Zanella M: Pseudomesotheliomatous angiosarcoma: a pleuropulmonary lesion simulating malignant pleural mesothelioma. Histopathology 1997, 30(5):419-424.

9. Alexiou C, Clelland CA, Robinson D, Morgan WE: Primary angiosarcomas of the chest wall and pleura. Eur J Cardiothorac Surg 1998, 14(5):523-526.

10. Attanoos RL, Suvarna SK, Rhead E, Stephens M, Locke TJ, Sheppard MN, Pooley FD, Gibbs AR: Malignant vascular tumours of the pleura in "asbestos" workers and endothelial differentiation in malignant mesothelioma. Thorax 2000, 55(10):860-863.

11. Zhang PJ, Livolsi VA, Brooks JJ: Malignant epithelioid vascular tumors of the pleura: report of a series and literature review. Hum Pathol 2000, 31(1):29-34.

12. Roh MS, Seo JY, Hong SH: Epithelioid angiosarcoma of the pleura: a case report. J Korean Med Sci 2001, 16(6):792-795.

13. Liu SF, Wu CC, Lai YF, Hsieh MJ: Massive hemoptysis and hemothorax caused by pleuropulmonary angiosarcoma. Am J Emerg Med 2002, 20(4):374-375.

14. Del Frate C, Mortele K, Zanardi R, Hunsaker AR, Nikpoor N, Cibas ES, Silverman SG: Pseudomesotheliomatous angiosarcoma of the chest wall and pleura. J Thorac Imaging 2003, 18(3):200-203.

15. Kimura M, Ito H, Furuta T, Tsumoto T, Hayashi S: Pyothorax-associated angiosarcoma of the pleura with metastasis to the brain. Pathol Int 2003, 53(8):547-551.

16. Varsano S, Edelstein E, Gendel B, Smorzik J: Bilateral and unilateral spontaneous massive hemothorax as a presenting manifestation of rare tumors. Respiration 2003, 70(2):214-218.

17. Chen L, Shih HJ, Seguerra E Jr, Lin JH: Pathologic quiz case: a 39-year-old man with diffuse pleural thickening and massive hemothorax.
Epithelioid angiosarcoma of pleura. Arch Pathol Lab Med 2004, 128(11):1299-1300.

18. Kurtz JE, Serra S, Duclos B, Brolly F, Dufour P, Bergerat JP: Diffuse primary angiosarcoma of the pleura: a case report and review of the literature. Sarcoma 2004, 8(4):103-106.

19. Maglaras GC, Katsenos S, Kakadelis J, Katsanos C, Metafratzi Z, Stefanou DG, Vassiliou MP, Constantopoulos SH: Primary angiosarcoma of the lung and pleura. Monaldi Arch Chest Dis 2004, 61(4):234-236.

20. Pramesh CS, Madur BP, Raina S, Desai SB, Mistry RC: Angiosarcoma of the pleura. Ann Thorac Cardiovasc Surg 2004, 10(3):187-190.

21. Kusano N, Nishikawa M, Ito M, Kakemizu N: [An autopsy case of chronic empyema-associated angiosarcoma that presented with a rapidly growing chest wall mass]. Nihon Kokyuki Gakkai Zasshi 2008, 46(3):248-252.

22. Saitou M, Niitsuma K: [A case of pyothorax-associated pleural angiosarcoma diagnosed by autopsy]. Kekkaku 2009, 84(7):531-534.

23. Hart J, Mandavilli S: Epithelioid angiosarcoma: a brief diagnostic review and differential diagnosis. Arch Pathol Lab Med 2011, 135(2):268-272.

24. Myoui A, Aozasa K, luchi K, Mori T, Yamamoto S, Kuratsu S, Ohsawa M, Ono K, Matsumoto K: Soft tissue sarcoma of the pleural cavity. Cancer 1991, 68(7):1550-1554

25. Hattori H: Epithelioid angiosarcoma arising in the tuberculous pyothorax: report of an autopsy case. Arch Pathol Lab Med 2001, 125(11):1477-1479.

doi:10.1186/1746-1596-6-130

Cite this article as: Kao et al:: Primary pleural angiosarcoma as a mimicker of mesothelioma: a case report. Diagnostic Pathology 201 6:130.

\section{Submit your next manuscript to BioMed Central and take full advantage of:}

- Convenient online submission

- Thorough peer review

- No space constraints or color figure charges

- Immediate publication on acceptance

- Inclusion in PubMed, CAS, Scopus and Google Scholar

- Research which is freely available for redistribution

Submit your manuscript at www.biomedcentral.com/submit
Ciomed Central 